\title{
Applicability of Foam Mat Drying Process for Production of Instant Cocoa Powder Enriched with Lavender Extract ${ }^{\S}$
}

\author{
Ana Maria Buljat, Tamara \\ Jurina*®, Ana Jurinjak Tušek®, \\ Davor Valinger®, Jasenka \\ Gajdoš Kljusurić@ and \\ Maja Benković@
}

University of Zagreb, Faculty of Food Technology and Biotechnology, Pierottijeva 6, 10000 Zagreb, Croatia

Received: 27 September 2018 Accepted: 17 June 2019

\footnotetext{
${ }^{*}$ Corresponding author:

Phone: +38514605021

Fax: +38514836083

E-mail: tlekic@pbf.hr
${ }^{\text {sPaper was presented at the } 9 \text { th }}$ International Congress of Food Technologists, Biotechnologists and Nutritionists, 3-5 October 2018, Zagreb, Croatia

\section{SUMMARY}

The foam mat drying process is a simple and economical alternative to spray and freeze drying. It is considerably cheaper due to rapid drying at low temperatures, preservation of nutritional quality and easy reconstitution. Basic principle of the process is conversion of a liquid or a semi-liquid foodstuff to foam and thin layer drying of the foam. This study explores the possibility of the foam mat drying for production of instant cocoa powder enriched with lavender (Lavandula $\times$ hybrida $\mathrm{L}$.) extracts. The aqueous extraction of lavender was optimized using Taguchi orthogonal array design. Extracts obtained under optimal conditions were added to a mixture of egg white, cocoa powder, sugar and gelatine. Mixtures were blended for $4 \mathrm{~min}$ to obtain stable foam which was dried at three different temperatures $\left(t=50,60\right.$ and $\left.70^{\circ} \mathrm{C}\right)$ and milled into a powdered product. Drying rates were obtained from the experimental data using nonlinear model estimation. Flow properties, bulk density, particle size distribution, reconstitution and sensory properties of the final product were also assessed. Based on the obtained data, the drying process was best described by Page's drying model. Samples dried at lower temperature $\left(t=50^{\circ} \mathrm{C}\right)$ exhibited the best powder flow and reconstitution properties. Sensory analysis resulted in similar findings: powder samples dried at lower temperatures had better appearance, colour and taste. The obtained data confirm the suitability of the foam mat drying for the production of instant cocoa powder enriched with lavender extract.

Key words: foam mat drying, cocoa, lavender, powder flow, modelling

\section{INTRODUCTION}

Drying is one of the oldest and most widespread food conservation methods during which water is removed from the foodstuff resulting in dry food material with extended shelf life due to low moisture content (1). During drying, changes can occur in composition and texture of foodstuffs, including nonenzymatic browning, loss of bioactive compounds or decrease of rehydration capacity of the dried foodstuff (2). The food industry aims towards solving these problems by utilization of novel drying processes or the reinstallation of the existing ones, optimized to achieve minimal nutritive loss, minimal texture changes and the best sensory properties of the final product with the lowest possible economic cost.

Foam mat drying is one of the re-emerging drying processes which has been known since 1959, but relinquished due to high economic costs of the first patented process (2). However, recent literature data states that the foam drying today is reported to be considerably cheaper than vacuum, freeze and spray drying methods $(1,3)$. The advantages of the foam mat drying include suitability for all types of juices, rapid drying at lower temperature, retention of nutritional quality, easy reconstitution and cost-effectiveness of production of easily reconstitutable powder $(3,4)$. There is literature proof of the application of the foam mat drying in processing of fruit juices and pulp (5-13), shrimp puree (14), vegetable puree $(15)$, fruit extracts $(16,17)$ and even seed extracts $(18)$, with most of them being categorised as sticky, high sugar content materials which usually cause problems when 
dried by any other drying method (e.g. spray or drum drying). The use of foam mat drying for the production of cocoa powder drink mixes still has not been explored, although these mixes belong into the group of high sugar content and sticky materials which are usually foam dried. This paper, therefore, evaluates the possibility and adequacy of the foam mat drying for the production of cocoa powder drink mix.

One of the reasons for choosing the cocoa powder as a material for the foam mat drying is its abundance in bioactive compounds, especially polyphenols (19). There are three groups of polyphenolics commonly occurring in cocoa products: flavonoids, anthocyanins and proanthocyanidins (20), known for their anticancerogenic, vasodilatory and anti-inflammatory effects (21-23). Interestingly, although abundant in bioactive compounds, cocoa powder and other cocoa products are being used as vehicles for the addition of other functional compounds such as vitamins, minerals or, more recently, herbal extracts. Herbal extracts are added to cocoa products not only because of their ability to enhance functional properties, but also due to their ability to affect taste and colour of such products $(24,25)$.

Lavender, a plant from the Lamiaceae family, is known as a medicinal and aromatic plant. It is mostly used for the production of essential oils, which are further used in cosmetic and pharmaceutical industry. Another use that is gaining popularity is as a tea plant since recent studies revealed that, besides essential oils, it is rich in bioactive compounds such as ferulic acid, ursolic acid and kaempferol malonyl glucoside (26). In that way it can act as an aroma compound in food products and also as a bearer of functional properties. Although its extract can be added directly to food products, in order to preserve functional properties and stability of heat-sensitive constituents a microencapsulated form of the extract is often used.

This study explores the possibility of using the foam mat drying process for the production of instant cocoa powder enriched with lavender (Lavandula $\times$ hybrida L.) extracts. The extract was added in two different forms: liquid and microencapsulated. Drying kinetics at three different temperatures ( $t=50,60$ and $70^{\circ} \mathrm{C}$ ) was described, as well as the physical, chemical and sensory properties of the obtained foam samples and the final powdered products.

\section{MATERIALS AND METHODS}

\section{Materials}

Lavandula $\times$ hybrida L. dried plant material used in this study was obtained from a local manufacturer (Suban, Strmec Samoborski, Croatia), harvested in the Međimurje county, Croatia, during the 2015 flowering season. Liquid egg white was obtained from Elcon (Elcon prehrambeni proizvodi d.o.o., Zlatar Bistrica, Croatia), pork gelatine from Podravka (Podravka, Koprivnica, Croatia) and edible sunflower oil from Čepin (Čepin tvornica ulja, Čepin, Croatia). Sucrose and cocoa powder with 10-12 \% fat content were obtained from Kraš (Kraš, Zagreb, Croatia).

\section{Chemicals and reagents}

Folin-Ciocalteu's reagent and sodium carbonate were purchased from Kemika (Zagreb, Croatia). Trolox (6-hydroxy-2,5,7,8-tetramethylchromane-2-carboxylic acid) was obtained from Fluka (Buchs, Switzerland). Gallic acid (3,4,5-trihydroxybenzoic acid) and 1,1-dyphenyl-2-picrylhydrazyl (DPPH) were obtained from Sigma-Aldrich Chemie, Merck (Steinheim, Germany), methanol was obtained from J.T.Baker (Phillipsburg, NJ, USA) and glycerol (85 \%) from a local pharmacy (Gradska ljekarna Zagreb, Zagreb, Croatia).

\section{Extract preparation}

The extract was prepared by weighing $4 \mathrm{~g}$ herbal material which was then mixed with $200 \mathrm{~mL}$ distilled water. The glass containing the mixture was then put in an IKA ${ }^{\circledR}$ HBR 4 digital oil bath (IKA Werke, Staufen, Germany) equipped with a magnetic stirrer set at $250 \mathrm{rpm}$ and heated to $80^{\circ} \mathrm{C}$. The extraction conditions were chosen based on a preliminary optimizing experiment using the Taguchi method (results not shown in this paper) (27). After $90 \mathrm{~min}$, the mixture was taken out from the oil bath, cooled in a water/ice mixture and filtered through a cellulose filter paper (LLG Labware, Meckenheim, Germany) with 5-13 $\mu \mathrm{m}$ pore size. Half of the extract was used in further experiments as is, while the other half was used to prepare the microencapsulated extract.

\section{Microencapsulated extract preparation}

Matrix type microcapsules containing lavender extract were prepared by adding $0.8 \mathrm{~g}$ glycerol and $2 \mathrm{~g}$ gelatine to $20 \mathrm{~mL}$ liquid lavender extract. The solution was then left to cool in a refrigerator for $10 \mathrm{~min}$. After $10 \mathrm{~min}$ the solution was heated to $80^{\circ} \mathrm{C}$ until all the gelatine was melted. The hot solution was then transferred in a syringe mounted on a NE-300 syringe pump (New Era Pump Systems, Farmingdale, NY, USA) with a flow rate of $1 \mathrm{~mL} / \mathrm{min}$. The solution was pumped through a syringe containing a microcapillary tip $(d=50 \mu \mathrm{m})$ into a glass filled with sunflower oil that was constantly cooled in an ice/water mixture. The formed microcapsules were stored in a refrigerator $\left(t=4-6{ }^{\circ} \mathrm{C}\right)$ for $60 \mathrm{~min}$ after which the suspension was filtered through a kitchen sieve. Prepared microcapsules were stored in a refrigerator until use.

\section{Foam mat drying of cocoa mixtures}

Three sets of experiments were prepared for foam mat drying: control set without the addition of lavender extract (set 1: samples K50, K60 and K70), a set containing the liquid lavender extract (set 2: samples L50, L60 and L70) and a set containing the microencapsulated lavender extract (set 3: samples M50, M60 and M70). All of the sets were prepared according to the same basic recipe: $150 \mathrm{~g}$ basic cocoa mixture (cocoa/sucrose in a 30:70 ratio), $180 \mathrm{~g}$ egg white and $0.5 \%$ $(\mathrm{m} / \mathrm{m})$ gelatine. Sets 2 and 3 also contained $5 \%(\mathrm{~m} / \mathrm{m})$ liquid 
extract and microencapsulated lavender extract, respectively. The mixtures were prepared by mixing the liquid ingredients (egg white and extract, if the mixture contained it) for 4 min using a kitchen blender (model HR 7628/00; Philips, Amsterdam, The Netherlands). Dry ingredients were then slowly added until homogenous foam was obtained. After mixing, the foam samples were evenly spread $(h=4 \mathrm{~mm}$ ) into aluminium trays, put in a convectional air dryer (model ST60T/EN; InkoLab, Zagreb, Croatia) and left to dry for $180 \mathrm{~min}$ at 50, 60 and $70^{\circ} \mathrm{C}$. The drying temperatures were selected based on temperature stability of polyphenols and antioxidants, which indicated that they are thermally stable at $50^{\circ} \mathrm{C}$ and their disintegration starts above $60^{\circ} \mathrm{C}$. Drying time was not reduced at higher drying temperatures to evaluate the changes in the quality of the powder under the given conditions. Dried foam samples were milled (model TUBE MILL C S000; IKA Werke, Staufen, Germany) at $15000 \mathrm{rpm}$ for $10 \mathrm{~s}$ in order to obtain a powdered product. The cocoa powder samples were stored in PE bags at $4^{\circ} \mathrm{C}$ until analysed.

\section{Modelling of the foam mat drying process}

During drying, experimental data for drying curves was obtained in the following manner: foam samples were taken from the dryer at 5-minute intervals, weighed using a TE214S analytical balance (Sartorius, Götingen, Germany) and the moisture ratio was calculated according to the following equation:

$$
\mathrm{MR}=\frac{w-w_{\mathrm{e}}}{w_{0}-w_{\mathrm{e}}}
$$

where MR is the dimensionless moisture ratio, $w$ is the moisture content measured at time $t, w_{0}$ is the initial moisture content and $w_{\mathrm{e}}$ is the equilibrium moisture content on dry mass basis (28).

The experimental data was used to calculate kinetic parameters of the drying process at three different temperatures $\left(t=50,60\right.$ and $70^{\circ} \mathrm{C}$ ) using three different thin layer drying models: Newton (Eq. 2), Henderson-Pabis (Eq. 3) and Page (Eq. 4), as described previously (28-30):

$$
\begin{gathered}
\mathrm{MR}=\mathrm{e}^{-\mathrm{kt}} \\
\mathrm{MR}=a \cdot \mathrm{e}^{-\mathrm{kt}} \\
\mathrm{MR}=\mathrm{e}^{-\mathrm{kt}^{\mathrm{N}}}
\end{gathered}
$$

where MR is the dimensionless moisture ratio, $k$ is the drying rate constant $\left(\mathrm{min}^{-1}\right), t$ is time (min), $a$ and $N$ are empirical constants of the models. The adequacy of the models for the determination of the drying rates and the prediction of the moisture content at any given time of the drying experiment was assessed based on the determination coefficient $\left(R^{2}\right)$ and root mean squared error (RMSE), as previously described by Benković et al. (28). Mathematical modelling of the experimental data was performed using the StatSoft Statistica v. 8.0 software package $(28,31)$.

\section{Foam density and foam stability}

Foam density was estimated as the ratio between the mass and volume of the foam. Foam stability was measured as the ratio of foam volume immediately after mixing and after $2 \mathrm{~h}$ of storage at room temperature (18).

\section{Dry matter of the foam and dried powder samples}

Dry matter of the foam and the dried powder samples was determined based on a standard AOAC method (32) in convection oven (INKOLAB Zagreb, Croatia). All measurements were performed in triplicate.

\section{Particle size distribution of the foam mat dried powder}

Particle size distribution was determined by a laser diffraction method with Malvern Mastersizer 2000 instrument and a Scirocco 2000 dry dispersion unit (Malvern Instruments, Malvern, UK). The laser obscuration was set to 2-6\%, feed rate to $60 \%$ and air pressure to $100000 \mathrm{~Pa}$. All analyses were performed in triplicate.

\section{Bulk density of the dried powder}

Bulk density was determined according to a method previously described by Haugaard Sørensen et al. (33), using a laboratory-made jolting volumeter. The bulk density of each sample was determined using the mass/volume relationship. Powder was poured into a graduated empty plastic container of predetermined tare mass, the mass and the volume of the sample in the container were recorded and bulk density was calculated by dividing sample mass with the sample volume, read after 10 vibrations, in order to minimise the error originating from uneven settlement of the powder surface in the measuring cylinder. Measurements were performed in triplicate.

\section{Cohesion and caking of the dried powder}

Cohesion and caking properties were assessed by a powder rheometer method (34). The cohesion test begins with two conditioning cycles to remove any stress history from the powder and to normalise the powder column after filling. The powder blade then moves down through the powder column using a 'cutting' action to minimise compaction. The upward part of the cycle lifts the powder and the force of the powder on the vessel base is recorded. The negative area under the curve is the work required to move the blade through the powder column, which represents the cohesion coefficient. A cohesion index is calculated by dividing the cohesion coefficient by the mass of the sample (34).

The caking test begins with two conditioning cycles; the blade then levels the top of the powder column and measures its height. The blade moves down through the column and compacts the powder to a pre-defined force (usually 750 g). When it reaches this force, it slices up through the powder and then repeats the compaction cycle four more times. The 
fifth time the target force is reached, the blade cuts through the cake of powder formed at the bottom of the vessel. This force is recorded as the cake strength and is the work required to cut the cake $(\mathrm{g} \cdot \mathrm{mm})$ and the mean cake strength is the average force required to cut the cake (g) (34).

\section{Reconstitution properties}

Reconstitution properties of the foam mat-dried powder were assessed as solubility and dispersibility. Solubility was determined according to a modified method by Haugaard Sørensen et al. (33). Approximately $2 \mathrm{~g}$ of sample were weighed and $10 \mathrm{~mL}$ of distilled water were added to the beaker containing the sample. The mixture was stirred with a spatula for $90 \mathrm{~s}$ and then left to settle for $15 \mathrm{~min}$. After that, two 5-minute centrifugation cycles were performed (Type 2000; Hettich, Tuttlingen, Germany) at 2012×g. After centrifugation, the volume of the sediment in the centrifuge tube $(\mathrm{mL})$ represented solubility (35).

Dispersibility was determined by a stirring test, as the time in seconds taken to disperse a given amount of powder into a given amount of water at a given temperature (33). A volume of $50 \mathrm{~mL}$ of distilled water $\left(t=24^{\circ} \mathrm{C}\right)$ was poured into a beaker and $5 \mathrm{~g}$ of sample were added. At the same time, stop watch was started and manual stirring began (approx. 25 circular stirring movements within $15 \mathrm{~s}$ ). Measurement was completed when all the lumps were dispersed (35).

\section{Total polyphenolic content and antioxidant capacity of the foam and dried powder samples}

Total polyphenolic content (TPC) of samples was determined according to a modified method of Lachman et al. (36). Measurements were carried out in triplicate and the results were expressed in mg of gallic acid equivalents (GAE) per dry mass of sample and derived from a calibration curve determined for gallic acid $(0-500 \mathrm{mg} / \mathrm{L})$.

Antioxidant capacity $(A O C)$ was determined using the DPPH method, previously described by Brand-Williams et al. (37). Results were expressed in $\mu \mathrm{mol}$ of Trolox equivalents per dry mass of sample and derived from a calibration curve determined for Trolox (0-1 $\mu \mathrm{mol} / \mathrm{L})$. Measurements were performed in triplicate.

\section{Sensory properties}

Sensory properties of the formulated mixtures were evaluated according to a hedonistic scale. Panellists $(N=5)$, at the age from 25 to 40, three female and two male, trained according to a multi-step procedure presented by Silva et al. (38) were asked to evaluate the prepared drinks based on appearance, colour, odour, sweetness, aftertaste and lavender aroma. The drinks were prepared in the following manner: $5 \mathrm{~g}$ of cocoa powder was dissolved in $100 \mathrm{~mL}$ of milk with $2.8 \%$ fat (Dukat, Zagreb, Croatia), previously heated to $90^{\circ} \mathrm{C}$. The prepared drinks were left to cool to $40-45^{\circ} \mathrm{C}$ before they were served to the panellists in $100-\mathrm{mL}$ plastic cups, starting with the control sample (K50, K60 and K70), followed by the samples containing the liquid extract (L50, L60 and L70) and ending with the powder samples containing the microencapsulated extract (M50, M60 and M70). Water was used for mouth rinsing. Sensory analysis was conducted at ambient conditions of $19{ }^{\circ} \mathrm{C}$ and a relative humidity of $45 \%$. Drinks were evaluated based on a scale from 1 to 9 (1=dislike extremely, $9=$ =like extremely).

\section{Data analysis}

Differences between measurements for a given property were analysed by ANOVA with $p<0.05$ taken as the significance level. In order to estimate a combined effect of temperature and extract type on physical, chemical and sensory properties of foam mat-dried powder, main effects ANOVA (MANOVA) was performed using the StatSoft Statistica software, v. $8.0(28,31)$. Differences among samples were considered significant at $\mathrm{p}<0.05$.

\section{RESULTS AND DISCUSSION}

Applicability of the foam mat drying process for the production of cocoa powder enriched with lavender extract, as well as the effect of three drying temperatures ( $t=50,60$ and $70{ }^{\circ} \mathrm{C}$ ) and extract type (no extract, liquid extract and microencapsulated extract) on physical, chemical and sensory properties was estimated in this research.

\section{Drying kinetics}

For each drying temperature applied in this study, drying curves were constructed and mathematical models were used to calculate the kinetic parameters of the drying process. Results are shown in Table 1: set 1 (control samples, without the addition of lavender extracts) had drying rate constants ranging from $k=0.0070 \mathrm{~min}^{-1}$ (at $t=50^{\circ} \mathrm{C}$ ) to $k=0.0080 \mathrm{~min}^{-1}$ (at $t=70^{\circ} \mathrm{C}$ ) calculated from the Newton model. For the Page model, the calculated constants were as follows: $k=0.0194$, 0.0322 and $0.0379 \mathrm{~min}^{-1}$ at $t=50,60$ and $70^{\circ} \mathrm{C}$, respectively. Drying rate constants calculated using the Henderson-Pabis model were lower than the ones determined by the Newton and Page: $k=0.0063,0.0060$ and $0.0068 \mathrm{~min}^{-1}$ at $t=50,60$ and $70{ }^{\circ} \mathrm{C}$, respectively. It can be concluded that drying at higher temperatures resulted in higher drying rate constants due to better diffusivity of the moisture towards the surface of the foam as a consequence of increased kinetic energy (2). An exception is observable in the data for drying rate obtained by the Henderson-Pabis model, where the drying rate was the highest at $t=70^{\circ} \mathrm{C}$, but at the two lower temperatures it did not show a rising trend. Since the difference is seen in the fourth digit after the decimal point $\left(k=0.0063 \mathrm{~min}^{-1}\right.$ at $t=50$ ${ }^{\circ} \mathrm{C}$ in comparison to $k=0.0060 \mathrm{~min}^{-1}$ at $t=60{ }^{\circ} \mathrm{C}$, with a standard error of $0.0002 \mathrm{~min}^{-1}$ for $k$ at $t=50{ }^{\circ} \mathrm{C}$ and $0.0003 \mathrm{~min}^{-1}$ for $k$ at $\left.t=50^{\circ} \mathrm{C}\right)$, the difference can be attributed either to 
Table 1. Parameters estimated with Newton, Page and Henderson-Pabis models for foam mat drying at 50,60 and $70^{\circ} \mathrm{C}$. Bold indicates the model that describes the experimental data the best

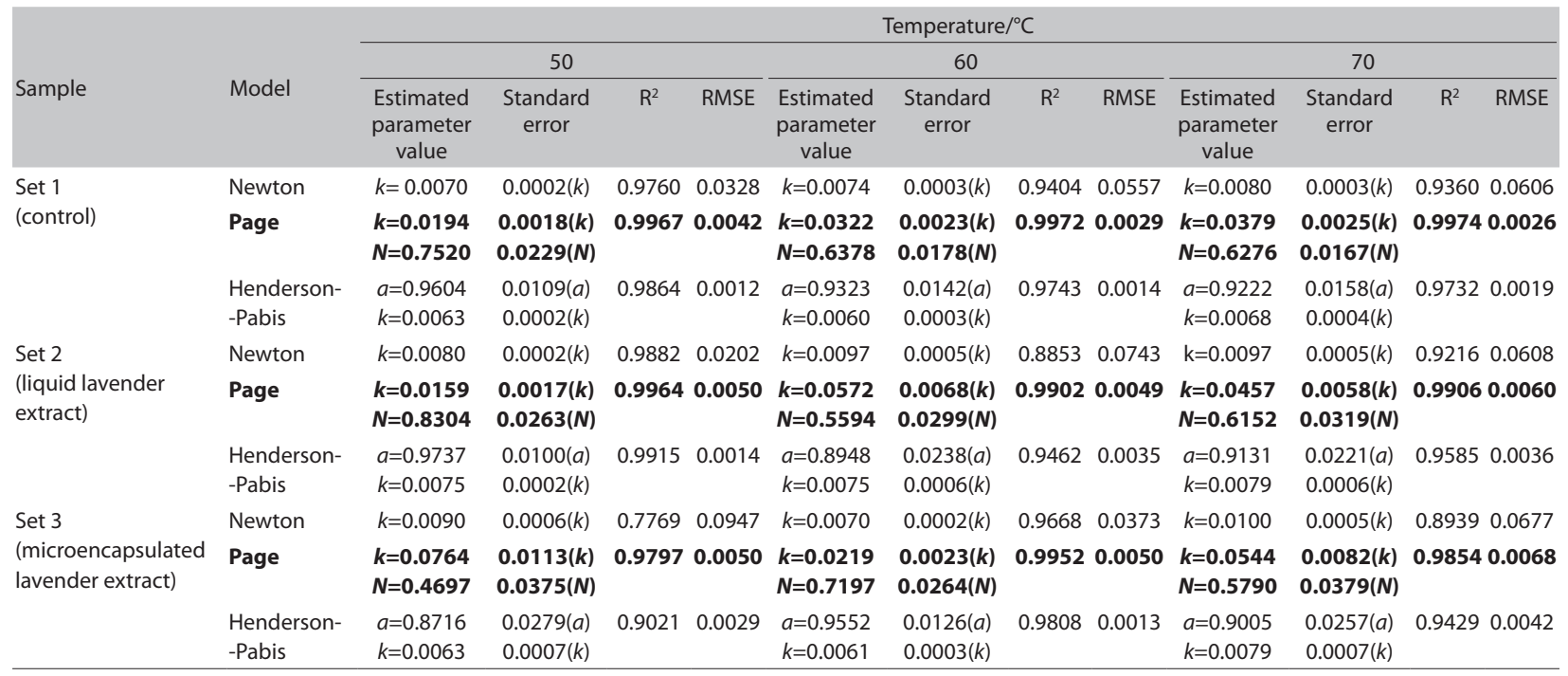

$k=$ drying rate constant $\left(\mathrm{min}^{-1}\right), a$ and $\mathrm{N}=$ empirical constants of the models, RMSE=root mean squared error

experimental error or the approximation error used by the Levenberg-Marquardt algorithm in the Statistica software (31) during modelling. In the case of the liquid lavender extract addition, the drying rate constants were higher than the drying rate constants without the added extract. This can be explained by the higher initial moisture content of the foam, since the direct addition of the liquid extract leads to an increase in moisture content. Due to the presence of higher amounts of moisture in the foam, there is also more moisture that can evaporate from the foam. The highest drying rate constants were obtained for the drying process at $70^{\circ} \mathrm{C}$ when using the Newton and Henderson-Pabis models, while the Page model exhibited an exception at $50{ }^{\circ} \mathrm{C}$ with the highest $k$ detected for the sample with the added $\mathrm{mi}$ crocapsules $\left(k=0.0764 \mathrm{~min}^{-1}\right)$. When the microencapsulated extract was added to the samples, the drying rate constants did not exhibit a rise with an increase of temperature. For instance, the highest drying rate constants determined by the Newton and the Henderson-Pabis models were detected at $70{ }^{\circ} \mathrm{C}$, followed by the ones at 50 and $60^{\circ} \mathrm{C}$, while with the Page model the highest drying rate was detected at $50^{\circ} \mathrm{C}$ drying temperature. The discrepancies in the results can be explained by the presence of gelatine as the matrix material for the microcapsules. Namely, gelatine is known as a polymeric substance that is very often used in the food industry as a gelling agent (39). According to literature data (40), at temperatures above $50{ }^{\circ} \mathrm{C}$, gelatine exists in a solution as a monomer, while above $60^{\circ} \mathrm{C}$ it undergoes glass transition. During cooling, gelatine network is formed, which affects the thermal properties of the solution (40). Furthermore, an increase of the temperature for drying gelatine from 10 to 70 ${ }^{\circ} \mathrm{C}$ decreases the content of crystalline structures and increases the content of amorphous structures (41), which also affects thermal properties of the solution. A change in gelatine structure could be the explanation of the differences in the drying rate; however, this claim needs to be supported by at least an environmental scanning electron microscope (ESEM) image, or differential scanning calorimetry (DSC), which is a subject of future research.

Based on the coefficient of determination values and RMSE, the best agreement between the predicted model and experimental data was achieved with the Page model for all three sets of samples dried at all three tested temperatures (Table 1), confirming the applicability of the Page model for description of the thin layer foam mat drying process. Furthermore, the drying kinetics is influenced by both the drying temperature and the type of extract used. The highest drying rate was observed for samples with liquid extract (set 2), followed by the samples with microcapsules (set 3 ) and the samples without the addition of lavender extracts (set 1).

\section{Foam physical properties}

Table 2 shows the physical properties of foam (density, stability and dry matter content).

Table 2. Foam properties of the mixtures determined prior to drying

Sample $\quad \frac{\rho}{g / m L} \quad \frac{\begin{array}{c}\text { Foam } \\ \text { stability }\end{array} \frac{w \text { (dry matter) }}{\%}}{\%}$

\section{Set 1}

(control)

$(0.73 \pm 0.10)^{\mathrm{a}} \quad(99.99 \pm 0.01)^{*}$

$(53.21 \pm 0.55)^{\#}$

Set 2 (liquid

lavender extract)

$(0.53 \pm 0.04)^{b} \quad(99.99 \pm 0.01)^{*}$

$(53.26 \pm 0.77)^{5}$

Set 3

$\begin{array}{llll}\text { (microencapsulated } \quad(0.63 \pm 0.07)^{c} & (99.99 \pm 0.01)^{*} & (54.99 \pm 0.02)^{s}\end{array}$ lavender extract)

Different letters and symbols in the same column represent significant differences $(p<0.05)$ of the same parameter among different sets 
Foam density is an important property that influences the drying process, as well as the properties of the final product. Generally, foaming enables incorporation of air in the material that is dried, thus enhancing the drying process (9). Foam density values ranged from minimal $\rho=0.53$ (set 2 with the addition of liquid extract) to maximal $0.73 \mathrm{~g} / \mathrm{mL}$ (set 1, without extract addition) (Table 2). This range is in accordance with literature data for foam densities obtained for drying of cantaloupe using egg white and xanthan gum as foaming agents (12), sour cherry using egg white and methyl cellulose ( $1 \%$ ) as foaming agents and stabilizers (10) and yoghurt using methyl cellulose and egg albumin (42). However, these values are higher than literature findings $(13,15,17)$ where foam densities were much lower $(\rho=0.2-0.35 \mathrm{~g} / \mathrm{mL})$ due to larger amount of air incorporated in the foam. It is visible that the addition of the liquid extract reduces the foam density values significantly ( $p<0.05)$, enabling the foam to be more porous. The addition of microencapsulated extract had a similar effect on the foam density, but less pronounced than the liquid extract.

Foam stability values measured after $120 \mathrm{~min}$ of settlement at room temperature were $(99.99 \pm 0.01) \%$ (Table 2$)$ for all sample sets indicating that egg white is an excellent foaming agent and that mixing for 4 min is sufficient to obtain a stable foam. According to literature data (4), foam is considered mechanically and thermally stable to undergo the foam mat drying when there is no significant reduction of volume after one hour at room temperature, which was the case with all sample sets used in this research.
Dry matter content of the foam samples ranged from 53.21 to $54.99 \%$ (Table 2), which exceeded the minimal requirements for the foam mat drying set at $20 \%$ of dry matter (2). The highest foam dry matter was detected in the samples containing the microencapsulated extract (set 3), followed by the samples with the addition of the liquid extract (set 2) and finally the control samples (set 1), which is a logical result since sets 2 and 3 contained additional dry matter from the extracts and the microcapsules.

\section{Physical properties of the foam mat-dried powder}

Table 3 shows the results of the analyses of particle size distribution, bulk density, dry matter content, flow properties (cohesion index, mean cake strength) and the reconstitution properties (dispersibility and solubility) of the powder samples obtained after drying.

Particle size is one of the most important properties that affect the behaviour of powder during handling, transportation and storage (43). The median diameter $(d(0.5))$ of the foam mat-dried cocoa powder ranged from 148.12 (set 1, $t=70$ ${ }^{\circ} \mathrm{C}$ ) to $186.04 \mu \mathrm{m}$ (set $3, t=60^{\circ} \mathrm{C}$ ) (Table 3). When looking only at the control set, the particle size of the powder dropped significantly $(p<0.05)$ with a rise in drying temperature, which was an indication that higher drying temperatures produce brittle powder with less moisture. The same trend was observed in set 2 with the addition of the liquid extract. In the case of the addition of microencapsulated extract, the highest particle size was obtained in the powder dried at $60^{\circ} \mathrm{C}$.

Table 3. Physical properties of the foam mat-dried powder samples

\begin{tabular}{|c|c|c|c|c|}
\hline \multirow{2}{*}{ Sample } & \multirow{2}{*}{ Powder property } & \multicolumn{3}{|c|}{ Temperature $/{ }^{\circ} \mathrm{C}$} \\
\hline & & 50 & 60 & 70 \\
\hline \multirow{7}{*}{$\begin{array}{l}\text { Set } 1 \\
\text { (control) }\end{array}$} & $d(0.5) / \mu \mathrm{m}$ & $(169.74 \pm 0.54)^{\mathrm{a}^{*}}$ & $(154.18 \pm 2.55)^{b^{*}}$ & $(148.12 \pm 2.21)^{\mathrm{c}^{*}}$ \\
\hline & $\rho_{\mathrm{b}} /(\mathrm{g} / \mathrm{mL})$ & $(0.65 \pm 0.03)^{\mathrm{a}^{*}}$ & $(0.64 \pm 0.02)^{\mathrm{a}^{*}}$ & $(0.57 \pm 0.01)^{\mathrm{b}^{*}}$ \\
\hline & $w($ dry matter $) / \%$ & $(95.73 \pm 0.03)^{\mathrm{a}^{*}}$ & $(97.18 \pm 0.05)^{\mathrm{b}^{*}}$ & $(98.49 \pm 0.21)^{\mathrm{c}^{*}}$ \\
\hline & Cohesion index/mm & $(14.00 \pm 0.01)^{\mathrm{a}^{*}}$ & $(13.47 \pm 0.03)^{\mathrm{b}^{*}}$ & $(14.92 \pm 0.04)^{c^{*}}$ \\
\hline & Mean cake strength/(g.mm) & $(104.49 \pm 4.64)^{a^{*}}$ & $(47.43 \pm 4.99)^{\mathrm{b}^{*}}$ & $(113.72 \pm 11.18)^{\mathrm{a}^{*}}$ \\
\hline & Dispersibility/s & $(22.50 \pm 1.00)^{\mathrm{a}^{*}}$ & $(26.50 \pm 1.00)^{\mathrm{b}^{*}}$ & $(24.00 \pm 1.00)^{\mathrm{a}^{*}}$ \\
\hline & Solubility as $V$ (sediment)/mL & $(1.20 \pm 0.03)^{\mathrm{a}^{*}}$ & $(0.80 \pm 0.01)^{\mathrm{b}^{*}}$ & $(1.50 \pm 0.03)^{\mathrm{c}^{*}}$ \\
\hline \multirow{7}{*}{$\begin{array}{l}\text { Set } 2 \text { (liquid } \\
\text { lavender extract) }\end{array}$} & $d(0.5) / \mu \mathrm{m}$ & $(167.57 \pm 2.62)^{\mathrm{a} \#}$ & $(164.30 \pm 2.87)^{\mathrm{bt}}$ & $(160.55 \pm 1.22)^{\mathrm{b \#}}$ \\
\hline & $\rho_{\mathrm{b}} /(\mathrm{g} / \mathrm{mL})$ & $(0.60 \pm 0.01)^{\mathrm{a}^{*}}$ & $(0.60 \pm 0.04)^{\mathrm{a \#}}$ & $(0.59 \pm 0.02)^{b^{*}}$ \\
\hline & $w($ dry matter $) / \%$ & $(96.14 \pm 0.02)^{\mathrm{a} \#}$ & $(97.21 \pm 0.11)^{\mathrm{b}^{*}}$ & $(98.61 \pm 0.05)^{\mathrm{c}^{*}}$ \\
\hline & Cohesion index/mm & $(14.74 \pm 0.02)^{\mathrm{a \#}}$ & $(16.10 \pm 0.04)^{\mathrm{b \#}}$ & $(19.06 \pm 0.02)^{\mathrm{c \#}}$ \\
\hline & Mean cake strength/(g.mm) & $(93.41 \pm 3.88)^{\mathrm{a \#}}$ & $(60.33 \pm 5.16)^{\mathrm{b \#}}$ & $(155.36 \pm 4.00)^{c \#}$ \\
\hline & Dispersibility/s & $(23.50 \pm 0.50)^{\mathrm{a}^{*}}$ & $(32.00 \pm 1.00)^{\mathrm{b \#}}$ & $(23.00 \pm 1.00)^{\mathrm{a}^{*}}$ \\
\hline & Solubility as $V$ (sediment)/mL & $(1.20 \pm 0.03)^{\mathrm{a}^{*}}$ & $(1.50 \pm 0.05)^{\mathrm{b \#}}$ & $(1.50 \pm 0.05)^{\mathrm{b}^{*}}$ \\
\hline \multirow{7}{*}{$\begin{array}{l}\text { Set } 3 \text { (microencapsulated } \\
\text { lavender extract) }\end{array}$} & $d(0.5) / \mu \mathrm{m}$ & $(166.76 \pm 2.27)^{\mathrm{a} \#}$ & $(186.04 \pm 1.00)^{\mathrm{bs}}$ & $(158.79 \pm 2.15)^{\mathrm{c} \#}$ \\
\hline & $\rho_{\mathrm{b}} /(\mathrm{g} / \mathrm{mL})$ & $(0.53 \pm 0.02)^{\mathrm{a} \#}$ & $(0.58 \pm 0.01)^{\mathrm{bH}}$ & $(0.58 \pm 0.02)^{\mathrm{b}^{*}}$ \\
\hline & $w($ dry matter $) / \%$ & $(95.76 \pm 0.12)^{\mathrm{bH}}$ & $(97.43 \pm 0.02)^{\mathrm{bH}}$ & $(98.67 \pm 0.06)^{\mathrm{a}^{*}}$ \\
\hline & Cohesion index/mm & $(19.06 \pm 0.01)^{\mathrm{as}}$ & $(19.25 \pm 0.02)^{\mathrm{as}}$ & $(26.57 \pm 0.06)^{\mathrm{b} \$}$ \\
\hline & Mean cake strength/(g.mm) & $(72.90 \pm 6.49)^{\mathrm{a}}$ & $(67.01 \pm 2.08)^{\mathrm{a}}$ & $(227.94 \pm 5.3)^{\mathrm{b} \$}$ \\
\hline & Dispersibility/s & $(28.50 \pm 1.50)^{\mathrm{a} \#}$ & $(24.00 \pm 0.50)^{\mathrm{b}^{*}}$ & $(21.00 \pm 0.50)^{\mathrm{b} \#}$ \\
\hline & Solubility as $V$ (sediment)/mL & $(1.20 \pm 0.01)^{\mathrm{a}^{*}}$ & $(1.45 \pm 0.01)^{\mathrm{b \#}}$ & $(1.50 \pm 0.02)^{\mathrm{b}^{*}}$ \\
\hline
\end{tabular}

Different letters in the same row indicate significant differences of the same parameter at different temperatures. Different symbols in the same column indicate significant differences of the same parameter among different sets. $d(0.5)=$ median diameter 
As argued before, the explanation behind this effect can be attributed to gelatine properties, but these claims are still to be confirmed in future research. Furthermore, the effect of the type of added extract on particle size was the most evident in the treatment at $60^{\circ} \mathrm{C}$, where a significant rise in particle size was visible $(\mathrm{p}<0.05)$ : the lowest $d(0.5)$ was detected in the control sample set, followed by the liquid extract (set 2) and the microencapsulated one (set 3). At $70{ }^{\circ} \mathrm{C}$, only the control sample exhibited a significantly lower $(p<0.05)$ value of $d(0.5)$ than the values detected in sets 2 and 3 .

A drop in the bulk density values of the powder samples was detected with a rise in drying temperature in sets 1 and 2 , as confirmed by the significant differences in the bulk density shown in Table 3. The powder samples with the microencapsulated extract (set 3) exhibited an opposite trend, with significantly lower bulk density values detected in treatments at $50{ }^{\circ} \mathrm{C}$ and similar values of bulk density in the treatments at 60 and $70^{\circ} \mathrm{C}$, which can be attributed to gelatine properties. The effect of the type of extract was visible in the treatments at 50 and $60^{\circ} \mathrm{C}$ : the control samples had the highest values of bulk density, with the values dropping when a liquid extract was added towards the lowest values when the microencapsulated extract was added. Lower bulk density values mean that there is more air entrapped between or in the particle pores, which can be connected to the foam density values shown in Table 2. Namely, as argued before, addition of both types of extracts led to lower foam densities, entrapping more air in the voids between foam structures, which subsequently had an effect on lowering the bulk density of these powder samples.

The effect of the drying temperature on the dry matter content was the same in all three sets of experiments: increased drying temperature caused an increase in dry matter content of the dried powders, which is in accordance with literature data (42), since higher drying temperatures increase the kinetic energy of water molecules which need to migrate from the matrix and therefore accelerate the heat and mass transfer processes.

Powder flow properties were assessed rheometrically with two analyses: cohesion and caking. Cohesion index of the control samples (set 1) ranged from 13.47 to $14.92 \mathrm{~mm}$, categorising them from the easy flowing to cohesive samples (44). The control sample dried at $70^{\circ} \mathrm{C}$ exhibited the highest values of cohesion index, which can be connected to lower values of $d(0.5)$, since the literature states that the powder with lower particle sizes usually exhibits poorer flow properties (45). Increased drying temperature also led to an increase in cohesion index values in all sets, which can once again be explained by a decrease in particle size. Namely, lower particle size values increase the specific surface area of the particles making them more reactive and prone to cohesion and caking (45). The effect of extract addition was also visible: sets 2 and 3 exhibited significantly higher $(p<0.05)$ cohesion index values than the control set, which categorised these powder samples from very cohesive to extremely cohesive.
Unlike the cohesion index, the mean cake strength values did not show the same trend of temperature and extract addition dependence. It was visible in all the samples that the samples dried at $70^{\circ} \mathrm{C}$ exhibited the highest mean cake strength values, with their significant rise $(p<0.05)$ with the addition of extract. A rise in cake strength values with the addition of extracts was also detected when drying at $60^{\circ} \mathrm{C}$. However, an exact opposite was detected when drying at $t=50^{\circ} \mathrm{C}$ : mean cake strength value was the highest for set 1 , followed by sets 2 and 3 . It is also interesting to observe the lowest mean cake strength values of the powder samples dried at $60^{\circ} \mathrm{C}$. This could be explained by three adverse effects: firstly, the conformational changes of egg white appear at $60^{\circ} \mathrm{C}$, indicating possible protein coagulation (46) and thus an influence on caking properties. Secondly, the glass transition of sucrose occurs around $62-70^{\circ} \mathrm{C}(47)$, when structural changes can affect caking behaviour, and thirdly, the polymorphism of the fatty acids present in cocoa powder, which are known to have polymorphic effects, at $55^{\circ} \mathrm{C}$, when melting occurs, and then solidification up to $71^{\circ} \mathrm{C}$, when the fat melts again (48). Once again, we must emphasize that more research is needed to support these claims, preferably on simpler model mixtures comprising fewer components so each effect can be studied separately.

Reconstitution properties, estimated as dispersibility and solubility, ranged from 21 to $32 \mathrm{~s}$ for dispersibility and from 0.8 to $1.5 \mathrm{~mL}$ for solubility, which was in this case observed as volume of sediment left in the Falcon tube. Although significant differences were detected among samples, no confirmation of an undisputed rise or fall trend with an increase in drying temperature of the type of extract added could be drawn. We must emphasize that the methods chosen for the determination of solubility and dispersibility, although extensively used, in this case have proven to be too subjective (e.g. the readout of the volume of the sediment which was then shown as solubility was similar for all samples, as well as the visible estimation of whether the whole volume of the powder was dispersed in water at a given time readout), and we, therefore, recommend different methods to be used for such types of powder.

\section{Chemical properties of the foam samples and the foam mat-dried lavender-enriched cocoa powder samples}

Experimental results describing the total polyphenolic content (TPC) and the antioxidant capacity (AOC) of foam samples and the foam mat-dried powder are shown in Fig. 1. Data shown in Fig. 1a describes the TPC of the foam samples prior to drying and the foam mat-dried powder. The TPC (expressed as GAE on dry mass basis) of the foam ranged from $0.74 \mathrm{mg} / \mathrm{g}$ in the control foam to $0.81 \mathrm{mg} / \mathrm{g}$ in the foam with the microencapsulated extract, leading to a conclusion that the lavender extract addition contributed to the TPC of the foam. According to literature data, cocoa powder contains a certain amount of polyphenols (20), which is higher than 
the levels detected in this work. The reason for the reduced TPC of the mixtures used in this study is the addition of egg white as the foaming agent, which does not contain polyphenols. Furthermore, the addition of lavender extract could not make up for the addition of the egg white, so the TPC could not reach the levels present in pure cocoa powder. It can also be noticed that the TPC of the powder after drying was lower than prior to drying, indicating a thermal degradation of

a)
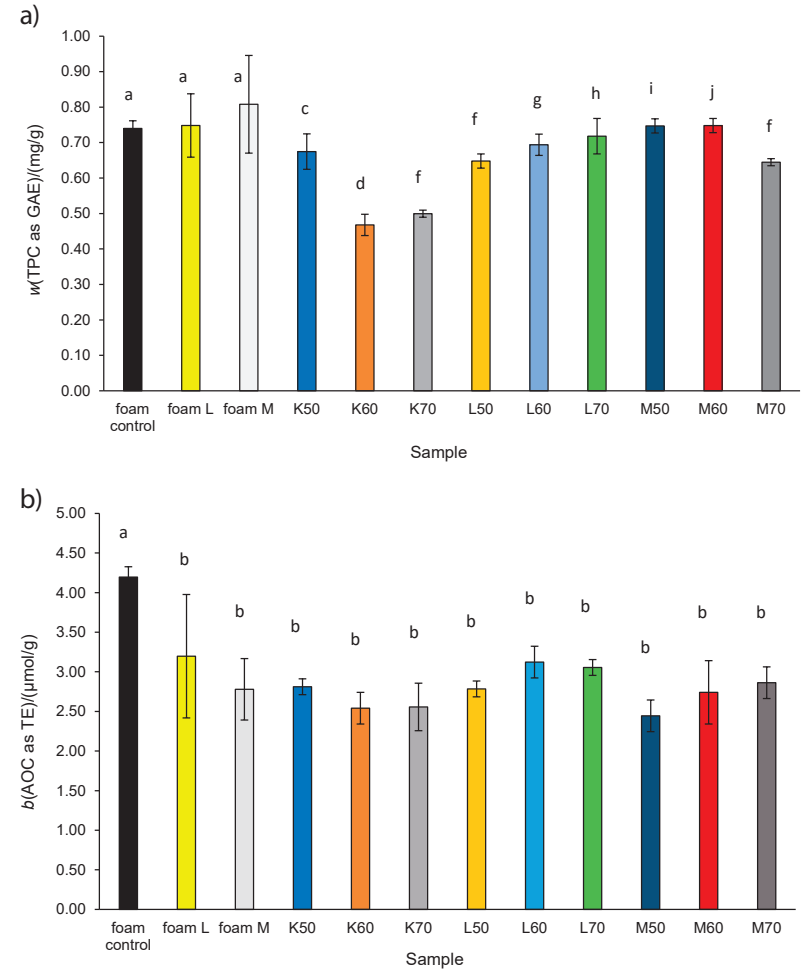

Fig. 1. Total polyphenolic content (TPC as gallic acid equivalents) (a) and the antioxidant capacity ( $\mathrm{OOC}$ as Trolox equivalents) (b) on dry mass basis of the foam samples and the foam mat-dried powder samples. Foam control=the foam sample without extract addition, foam $L=$ the foam with the liquid extract addition, foam $M=$ the foam with the microencapsulated extract addition. Samples K50, K60 and K70 represent set 1 (control samples without the addition of lavender extract dried at $t=50,60$ and $70{ }^{\circ} \mathrm{C}$ ), samples $L 50, L 60$ and $L 70$ represent set 2 (set containing the liquid lavender extract dried at $t=50,60$ and $70^{\circ} \mathrm{C}$ ), samples M50, M60 and M70 represent set 3 (set containing the microencapsulated lavender extract dried at $t=50,60$ and $70^{\circ} \mathrm{C}$ ). Different letters above the column represent significant differences $(p<0.05)$

phenolic compounds during the drying process. However, there are some studies available in the literature that have come to the opposite conclusions: Albernaz Lobo et al. (49) report a higher amount of total polyphenols after the drying of mango pulp. According to them, higher TPC is a consequence of heat treatment leading to a simplified extraction of the polyphenolic compounds from the food matrix. In control samples (set 1), higher drying temperatures resulted in the powder with lower TPC, which was also the case with the samples containing the microencapsulated extract. However, in sample set 2 higher drying temperatures resulted in higher
TPC values of the final powder. Similarly, Wojdyło et al. (50) conducted drying trials on cherries and concluded that the higher TPC is a result of the release of polyphenols from the cells during the heat treatment, which aided the extraction process. In this case, a possibility remains that the liquid extract was bound to the foam matrix and remained protected through the drying process and, in a way, concentrated with the increase of dry matter. However, we must emphasize that this still has to be confirmed by future research.

The highest antioxidant capacity values measured by the DPPH method (Fig. 1b), expressed as TE on dry mass basis, ranged from 4.20 (foam control) to $2.78 \mu \mathrm{mol} / \mathrm{g}$ (foam $\mathrm{M}$ ) of the foam samples prior to drying. After drying, the AOC values were significantly lower $(p<0.05)$ than the level of antioxidants detected in the foam control samples. Once again, the liquid extract proved to be more stable during drying in a given food matrix (egg white, sugar and gelatine) than the microencapsulated one. This could be explained by the fact that some polyphenols and antioxidants are known to bind and form stable complexes with proteins, which influences their physiological and chemical properties $(51,52)$.

\section{Sensory evaluation and consumer preferences of the foam mat-dried lavender-enriched cocoa powder}

Fig. 2 shows sensory analysis data for the foam mat-dried lavender-enriched cocoa powder.

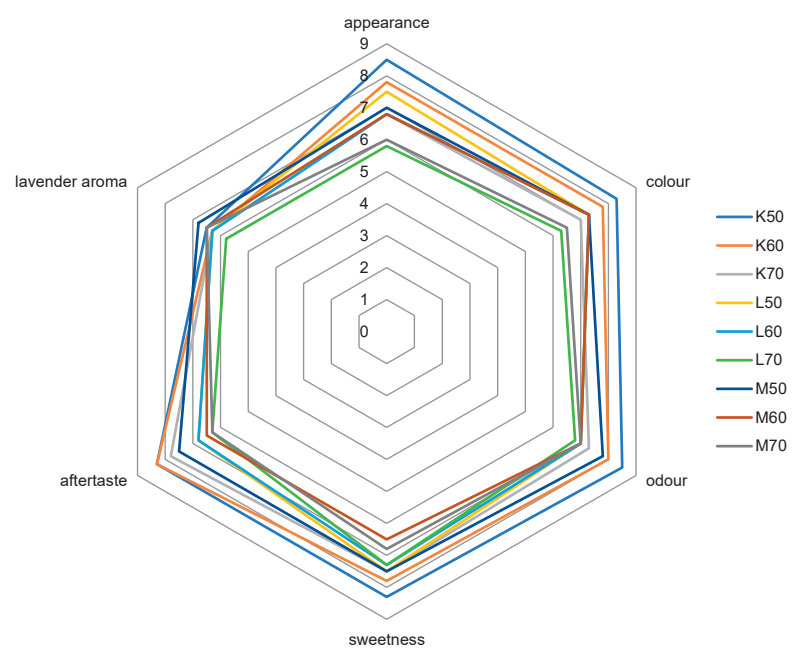

Fig. 2. Sensory evaluation of the drinks prepared with the cocoa powder enriched with foam mat-dried lavender extract. Samples K50, K60 and $\mathrm{K} 70$ represent set 1 (control set without the addition of lavender extract dried at $t=50,60$ and $70{ }^{\circ} \mathrm{C}$ ), samples $L 50, L 60$ and $L 70$ represent set 2 (set containing the liquid lavender extract dried at $t=50,60$ and $70^{\circ} \mathrm{C}$ ), samples $\mathrm{M} 50, \mathrm{M} 60$ and $\mathrm{M} 70$ represent set 3 (set containing the microencapsulated lavender extract dried at $t=50,60$ and $70^{\circ} \mathrm{C}$ )

Regarding the scores for the appearance of the drink, the best graded sample was $\mathrm{K} 50$, dried at $50^{\circ} \mathrm{C}$ and without the lavender extract. The lowest graded appearance was for sample L70, containing the liquid lavender extract and dried at $70{ }^{\circ} \mathrm{C}$. The samples also differed by colour grades, where the 
samples dried at the lowest temperature $\left(t=50^{\circ} \mathrm{C}\right)$ obtained higher grades than those dried at $70^{\circ} \mathrm{C}$. According to literature data, the drying (roasting) process has a significant effect on the quality of cocoa: the choice of an adequate drying temperature influences the characteristic cocoa aroma, loss of water, volatile acid and tannin compounds, as well as deepening of the brown colour of the bean and release of gaseous compounds (53). In this case, since the cocoa used was already roasted, drying at higher temperatures had deteriorating effect on the colour, as well as on the flavour of the powder. The same was observed for odour and sweetness. As for the grades for aftertaste and lavender aroma, it could be concluded that the lavender aroma was very pronounced in samples with liquid lavender extract, and less pronounced in those containing the microencapsulated extract. There are two explanations for such a finding: first, microencapsulation is used to mask undesirable flavours, which could have been the case in this study. The second explanation is connected to the composition of the powder samples. Namely, the powder containing the microencapsulated extract also contained $5 \%(\mathrm{~m} / \mathrm{m})$ of the microcapsules, but when considering that the microcapsules were made with the addition of $2 \mathrm{~g}$ gelatin per $20 \mathrm{~mL}$ extract, the mass fraction of lavender in those samples was slightly smaller. The most acceptable samples based on aftertaste were once again those dried at lower temperatures. These sensory scores lead to the conclusion that lower drying temperature resulted in drinks that had higher acceptability to consumers, while the lavender aroma was very much a matter of user preferences: some consumers preferred to taste the lavender aroma in the cocoa drink, while the others did not like it as much. Furthermore, the cocoa powder containing microencapsulated lavender extract had a slightly toned down lavender aroma, which was more acceptable for consumers.
Combined influence of the temperature and the extract type on physical, chemical and sensory properties of the foam mat-dried lavender extract-enriched cocoa powder

Combined influence of temperature and the added extract type was assessed using the main effects ANOVA (MANOVA). Results are shown in Table 4.

Significant influence of the drying temperature and the type of extract added to the mixtures was determined for the following properties: powder dry matter $\left(R^{2}=0.9823\right)$, cohesion index $\left(R^{2}=0.7919\right)$ and sensory properties: appearance $\left(R^{2}=0.9392\right)$, colour $\left(R^{2}=0.9274\right)$, odour $\left(R^{2}=0.7335\right)$, sweetness $\left(R^{2}=0.7827\right)$ and aftertaste $\left(R^{2}=0.8674\right)$ (Table 4). When dried at higher temperatures, the dry matter content of the resulting material is lower. The influence of the drying temperature and the extract type on the cohesion index of the powder can be attributed to the initial moisture content, which, when higher, influences the drying rates, as well as the final moisture content of the powder. According to literature data, powder flow properties highly depend on the moisture content: higher moisture content causes flow difficulties (45). Interestingly, MANOVA did not show a significant simultaneous effect of temperature and extract type on the TPC and $A O C$ of the dried powder samples. However, as mentioned before, significant differences were detected between the foam samples prior to drying and the powder samples after the drying. Influence of the drying temperature and the type of added extract on the sensory properties was observed in the cases when the consumers preferred the powder dried at lower temperatures $\left(t=50^{\circ} \mathrm{C}\right)$ and the masking of the lavender aroma when the microencapsulated extract was added. Although not significant based on the MANOVA results $(p=0.06)$, the influence of the lavender aroma cannot be completely excluded from the sensory analysis, since the lavender

Table 4. Main effects analysis of variance of the simultaneous influence of temperature and extract type on physical, chemical and sensory properties of the foam mat-dried lavender extract-enriched cocoa powder. Significant influences are printed in bold

\begin{tabular}{lccccc} 
Variable & Multiple & Multiple & Adjusted & F \\
$\mathrm{R}^{2}$ & $\mathrm{R}$ & 0.9911 & 0.9823 & 112.1057 & 0.0002 \\
Powder dry matter & 0.9956 & 0.6068 & 0.2136 & 1.5431 & 0.3422 \\
$d(0.5)$ & 0.7790 & 0.6262 & 0.2524 & 1.6751 & 0.3147 \\
Bulk density & 0.7913 & 0.8959 & 0.7919 & 8.6108 & 0.0302 \\
CI & 0.9465 & 0.7800 & 0.5600 & 3.5460 & 0.1239 \\
MCS & 0.8832 & 0.4397 & -0.1206 & 0.7848 & 0.5900 \\
Dispersibility & 0.6631 & 0.5580 & 0.1159 & 1.2623 & 0.4134 \\
Solubility & 0.7470 & 0.6768 & 0.3535 & 2.0938 & 0.2459 \\
TPC(powder) & 0.8227 & 0.6040 & 0.2080 & 1.5353 & 0.3462 \\
DPPH(powder) & 0.7718 & 0.9696 & 0.9392 & 31.8846 & 0.0027 \\
Appearance & 0.9847 & 0.9637 & 0.9274 & 26.5625 & 0.0038 \\
Colour & 0.9817 & 0.8668 & 0.7335 & 6.5061 & 0.0485 \\
Odour & 0.9310 & 0.8914 & 0.7827 & 8.2056 & 0.0328 \\
Sweetness & 0.9441 & 0.9337 & 0.8674 & 14.0823 & 0.0126 \\
Aftertaste & 0.9663 & 0.8506 & 0.7011 & 5.6923 & 0.0603 \\
Lavender aroma & 0.9223 & & & \\
\hline
\end{tabular}

$\mathrm{F}=$ variation between sample mean values and variation within the samples, $\mathrm{P}=$ significance level, $d(0.5)=$ median diameter, $\mathrm{Cl}=\mathrm{cohesion}$ index, MCS=mean cake strength, TPC=total polyphenolic content, DPPH=1,1-diphenyl-2-picrylhydrazyl 
plant contains essential oils that are known to have a strong effect on the organoleptic properties of food (54).

\section{CONCLUSION}

The foam mat drying process was applied to produce cocoa powder enriched with lavender extract. The effect of drying temperature was evident on the drying rate constants: higher drying temperatures increased the drying rate values (drying rate constants calculated with the Page model ranged from $k=0.0159$ to $0.0764 \mathrm{~min}^{-1}$ at $t=50^{\circ} \mathrm{C}$, from $k=0.0219$ to $0.0572 \mathrm{~min}^{-1}$ at $t=60{ }^{\circ} \mathrm{C}$, and from $k=0.0379$ to $0.0544 \mathrm{~min}^{-1}$ at $t=70^{\circ} \mathrm{C}$ ). The extract type also influenced the drying rates: lower constants calculated with the Page model were obtained for control samples, while higher values were obtained for liquid and microencapsulated extracts. Powder samples with the addition of the microencapsulated extracts had the highest cohesion index values. Temperature and extract type had a combined effect on the powder dry matter content, cohesion index, appearance, colour, odour, sweetness and aftertaste. Sensory properties depended on both the drying temperature and the extract type: the consumers preferred the powder dried at lower temperature $\left(t=50^{\circ} \mathrm{C}\right)$ and with the microencapsulated extract.

\section{FUNDING}

No funding data available.

\section{CONFLICT OF INTEREST}

The authors have no conflict of interest to declare.

\section{ORCID IDs}

T. Jurina (1) https://orcid.org/0000-0002-1695-6766

A. Jurinjak Tušek (1) https://orcid.org/0000-0002-3032-903X

D. Valinger (i) https://orcid.org/0000-0002-3353-1065

J. Gajdoš Kljusurić (iD https://orcid.org/0000-0001-6657-7337

M. Benković (i) https://orcid.org/0000-0003-2167-6862

\section{REFERENCES}

1. Sangamithra A, Sivakumar V, Swamy GJ, Kannan K. Foam mat drying of food materials: A review. J Food Process Preserv. 2015;39(6):3165-74.

https://doi.org/10.1111/jfpp.12421

2. Lovrić T. Processes in food industry - Basics of food engineering. Zagreb, Croatia: Hinus; 2003 (in Croatian).

3. Kadam DM, Balasubramanian S. Foam mat drying of tomato juice. J Food Process Pres. 2011;35(4):488-95. https://doi.org/10.1111/j.1745-4549.2010.00492.x

4. Kudra T, Ratti C. Foam-mat drying: Energy and cost analyses. Can Biosyst Eng. 2006;48:327-32.

5. Szlapak Franco T, Augusto Perussello C, de Souza Neves Ellendersen L, Masson, ML. Foam mat drying of yacon juice:
Experimental analysis and computer simulation. J Food Eng. 2015;158:48-57.

https://doi.org/10.1016/j.jfoodeng.2015.02.030

6. Vernon-Carter E, Espinosa-Paredes G, Beristain Cl, Romero-Tehuitzil $\mathrm{H}$. Effect of foaming agents on the stability, rheological properties, drying kinetics and flavour retention of tamarind foam-mats. Food Res Int. 2001;34(7):587-98.

https://doi.org/10.1016/S0963-9969(01)00076-X

7. Rajkumar P, Kailappan R, Viswanthan R, Raghavan GSV. Drying characteristics of foamed Alphonso mango pulp in a continuous type foam mat dryer. J Food Eng. 2007;79(4): 1452-9.

https://doi.org/10.1016/j.jfoodeng.2006.04.027

8. Abd Karim A, Chee Wai C. Foam-mat drying of starfruit (Averrhoa carambola L.) purée. Stability and air drying characteristics. Food Chem. 1999;64(3):337-43.

https://doi.org/10.1016/S0308-8146(98)00119-8

9. Thuwapanichayanan R, Prachayawarakorn S, Soponronnarit S. Drying characteristics and quality of banana foam mat. J Food Eng. 2008;86(4):573-83.

https://doi.org/10.1016/j.jfoodeng.2007.11.008

10. Abbasi E, Azizpour M. Evaluation of physicochemical properties of foam mat dried sour cherry powder. LWT - Food Sci Technol. 2016;68:105-10.

https://doi.org/10.1016/j.lwt.2015.12.004

11. Ambekar SA, Gokhale SV, Lele SS. Process optimization for foam mat-tray drying of Passiflora edulis flavicarpa pulp and characterization of the dried powder. Int J Food Eng. 2013;9(4):433-43.

https://doi.org/10.1515/ijfe-2012-0185

12. Reza Salahi M, Mohebbi M, Taghizadeh M. Foam-mat drying of cantaloupe (Cucumis melo): Optimization of foaming parameters and investigating drying characteristics. J Food Process Preserv. 2015;39(6):1798-808.

https://doi.org/10.1111/jfpp.12414

13. Prakotmak P, Soponronnarit S, Prachayawarakorn S. Modelling of moisture diffusion in pores of banana foam mat using a 2-D stochastic pore network: Determination of moisture diffusion coefficient during adsorption process. J Food Eng. 2010;96(1):119-26.

https://doi.org/10.1016/j.jfoodeng.2009.07.004

14. Azizpour M, Mohebbi M, Khodaparast MHH. Effects of foam-mat drying temperature on physico-chemical and microstructural properties of shrimp powder. Innov Food Sci Emerg Technol. 2016;34:122-6.

https://doi.org/10.1016/j.ifset.2016.01.002

15. Chandrasekar V, Gabriela JS, Kannan K, Sangamithra A. Effect of foaming agent concentration and drying temperature on physicochemical and antimicrobial properties of foam mat dried powder. Asian J Dairy Food Res. 2015;34(1): 39-43.

https://doi.org/10.5958/0976-0563.2015.00008.1 
16. Phaechamud T, Sarunyakasitrin K, Choncheewa C. Instant powder of malabar tamarind fruit extract prepared by foam-mat method. Adv Mater Res. 2012;506:351-4. https://doi.org/10.4028/www.scientific.net/AMR.506.351

17. Benstain $\mathrm{Cl}$, Garcia HS, Vasquez A. Foam mat dehydration of jamaica (Hibiscus sabdariffa L.) instant drink. Drying Technol. 1993;11(1):221-8. https://doi.org/10.1080/07373939308916811

18. Affandi N, Zzaman W, Yang TA, Easa AM. Production of Nigella sativa beverage powder under foam mat drying using egg albumen as a foaming agent. Beverages. 2017;3(1):1-15. https://doi.org/10.3390/beverages3010009

19. Ačkar $Đ$, Valek Lendić $K$, Valek $M$, Šubarić $D$, Miličević $B$, Babić J, Nedić I. Cocoa polyphenols: Can we consider cocoa and chocolate as potential functional food? J Chem. 2013;2013:Article ID 289392.

https://doi.org/10.1155/2013/289392

20. Wollgast J, Anklam E. Review on polyphenols in Theobroma cacao: Changes in composition during the manufacture of chocolate and methodology for identification and quantification. Food Res Int. 2000;33(6):423-47. https://doi.org/10.1016/S0963-9969(00)00068-5

21. Oleaga C, García M, Solé A, Ciudad CJ, Izquierdo-Pulido M, Noé V. CYP1A1 is overexpressed upon incubation of breast cancer cells with a polyphenolic cocoa extract. Eur J Nutr. 2012;51(4):465- 76.

https://doi.org/10.1007/s00394-011-0231-2

22. Vlachojannis J, Erne P, Zimmermann B, Chrubasik-Hausmann S. The impact of cocoa flavonols on cardiovascular health. Phytother Res. 2016;30(10):1641-57.

https://doi.org/10.1002/ptr.5665

23. Dugo L, Belluomo MG, Fanali C, Russo M, Cacciola F, Maccarrone M, Sardanelli AM. Effect of cocoa polyphenolic exstract on macrophage polarization from proinflammatory M1 to anti-inflammatory M2 state. Oxid Med Cell Longev. 2017;2017:Article ID 6293740.

https://doi.org/10.1155/2017/6293740

24. Belščak-Cvitanović A, Komes D, Benković M, Karlović S, Hečimović l, Ježek D, Bauman I. Innovative formulations of chocolates enriched with plant polyphenols from Rubus idaeus $\mathrm{L}$. leaves and characterization of their physical, bioactive and sensory properties. Food Res Int. 2012;48(2):820-30. https://doi.org/10.1016/j.foodres.2012.06.023

25. Carvalho Costa D, Costa HS, Gonçalves Albuquerque T, Ramos F, Castilho MC, Sanches-Silva A. Advances in phenolic compounds analysis of aromatic plants and their potential applications. Trends Food Sci Technol. 2015;45(2):336-54. https://doi.org/10.1016/j.tifs.2015.06.009

26. Spiridon I, Colceru S, Anghel N, Teaca CA, Bodirlau R, Armatu A. Antioxidant capacity and total phenolic contents of oregano (Origanum vulgare), lavender (Lavandula angustifolia) and lemon balm (Melissa officinalis) from Romania.
Nat Prod Res. 2011;25(17):1657-61.

https://doi.org/10.1080/14786419.2010.521502

27. Jurinjak Tušek $A$, Benković $M$, Belščak Cvitanović $A$, Valinger D, Jurina T, Gajdoš Kljusurić J. Kinetics and thermodynamics of the solid-liquid extraction process of total polyphenols, antioxidants and extraction yield from Asteraceae plants. Ind Crops Prod. 2016;91:205-14.

https://doi.org/10.1016/j.indcrop.2016.07.015

28. Benković M, Srečec S, Bauman I, Ježek D, Karlović S, Kremer $\mathrm{D}$, et al. Assessment of drying characteristics and texture in relation with micromorphological traits of carob (Ceratonia silliqua L.) pods and seeds. Food Technol Biotechnol. 2016; 54(4):432-40.

https://doi.org/10.17113/ftb.54.04.16.4475

29. Zhang $Y$, Chen $H$, Chen T. Drying kinetics of RDX under atmospheric pressure and vacuum conditions. Energy Convers Manag. 2014;80:266-75.

https://doi.org/10.1016/j.enconman.2014.01.039

30. Akpinar EK. Drying of mint leaves in a solar dryer and under open sun: Modelling, performance analyses. Energy Convers Manag. 2010;51(12):2407-18.

https://doi.org/10.1016/j.enconman.2010.05.005

31. Statistica, v. 8.0, StatSoft, Inc, Tulsa, OK, USA; 2008. Available from: http://www.statsoft.com.

32. AOAC Official Methods of Analysis. Determination of moisture content. Rockville, MD, USA: AOAC International; 1990.

33. Haugaard Sørensen I, Krag J, Pisecky J, Westergaard V, editors. Analytical methods for dry milk products. Copenhagen, Denmark: Niro Atomizer; 1978.

34. Janjatović $D$, Benković $M$, Srečec $S$, Ježek $D$, Špoljarić I, Bauman I. Assessment of powder flow characteristics in incoherent soup concentrates. Adv Powder Technol. 2012; 23(5):620-31.

https://doi.org/10.1016/j.apt.2011.07.003

35. Benković M, Radić K, Vitali Čepo D, Jaškunas E, Janutis $L$, Morkunaite M, Srečec S. Production of cocoa and carob-based drink powders by foam mat drying. J Food Process Eng. 2018;41(6):e12825:1-11.

https://doi.org/10.1111/jfpe.12825

36. Lachman J, Hosnedl V, Pivec V, Orsák M. Polyphenols in cereals and their positive and negative role in human and animal nutrition. Proceedings of the Conference Cereals for Human Health and Preventive Nutrition; 1998 July 7-11, Brno, Czech Republic: Agricultural Research Institute Kroměřǐž, Brno, Czech Republic; 1998. pp. 118-25.

37. Brand-Williams W, Cuvelier ME, Berset C. Use of a free radical method to evaluate antioxidant activity. LWT - Food Sci Technol. 1995;28(1):25-30.

https://doi.org/10.1016/S0023-6438(95)80008-5

38. Silva AYSL, Binduhewa AMCU, Subodinee AAM. A study to recruit and train the product oriented sensory panel, Int J Multidiscip Stud. 2014:1(2):83-7.

https://doi.org/10.31357/ijms.v1i2.55 
39. Gómez-Guillén MC, Giménez B, López-Caballero ME, Montero MP. Functional and bioactive properties of collagen and gelatin from alternative sources: A review. Food Hydrocoll. 2011;25(8):1813-27. https://doi.org/10.1016/j.foodhyd.2011.02.007

40. Parker NG, Povey MJW. Ultrasonic study of the gelation of gelatin: Phase diagram, hysteresis and kinetics. Food Hydrocoll. 2012;26(1):99-107. https://doi.org/10.1016/j.foodhyd.2011.04.016

41. Kato Y, Hagiwara T, Suzuki T, Takai R. The effect of thermal history on the glass transition of dried gelatine gel. Trans Mat Res Soc Japan. 2001;26(2):659-62.

42. Krasaekoopt W, Bhatia S. Production of yogurt powder using foam-mat drying. Au J T. 2012;15(3):166-71.

43. Fu X, Huck D, Makein L, Armstrong B, Willen U, Freeman T. Effect of particle shape and size on flow properties of lactose powders. Particuology. 2012;10(2):203-8. https://doi.org/10.1016/j.partic.2011.11.003

44. Benković M, Srečec S, Špoljarić I, Mršić G, Bauman I. Flow properties of commonly used food powders and their mixtures. Food Bioprocess Technol. 2013;6(9):2525-37. https://doi.org/10.1007/s11947-012-0925-3

45. Barbosa-Cánovas G, Ortega-Rivas E, Juliano P, Yan, H. Food powders. New York, NY, USA: Kluwer Academic/Plenum Publishers; 2005.

46. Moraes Santos Gomes MT, Guimarães Pelegrine DH. Solubility of egg white proteins: Effect of $\mathrm{pH}$ and temperature. Int J Food Eng. 2012;8(3). https://doi.org/10.1515/1556-3758.2847

47. Hartel RW, Ergun R, Vogel S. Phase/state transitions of confectionery sweeteners: Thermodynamic and kinetic aspects. Compr Rev Food Sci F. 2011;10(1):17-32. https://doi.org/10.1111/j.1541-4337.2010.00136.x
48. Maning DM, Dimick PS. Crystal morphology of cocoa butter. Food Struct. 1985;4(2):249-65.

49. Albernaz Lobo F, Abreu Nascimento M, Roberto Domingues J, Quintanilha Falcão D, Hernanz D, Heredia FJ, Gomes de Lima Araujo K. Foam mat drying of Tommy Atkins mango: Effects of air temperature and concentrations of soy lecithin and carboxymethylcellulose on phenolic composition, mangiferin, and antioxidant capacity. Food Chem. 2017;221:258-66.

https://doi.org/10.1016/j.foodchem.2016.10.080

50. Wojdyło A, Figiel A, Lech K, Nowicka P, Oszmiański J. Effect of convective and vacuum-microwave drying on the bioactive compounds, color, and antioxidant capacity of sour cherries. Food Bioprocess Technol. 2014;7(3):829-41

https://doi.org/10.1007/s11947-013-1130-8

51. Cömert ED, Gökmen V. Antioxidants bound to an insoluble food matrix: Their analysis, regeneration behavior, and physiological importance. Compr Rev Food Sci Food Saf. 2017;16(3):382-99.

https://doi.org/10.1111/1541-4337.12263

52. Sun X, Engstrom MT, Salminen JP, Hagerman AE. Polyphenol antioxidants bind irreversibly to protein under oxidative conditions. FASEB J. 2017;31(Suppl. 1):Abstract No.646. 9.

53. Krysiak W, Adamski R, Żyżelewicz D. Factors affecting the color of roasted cocoa bean. J Food Qual. 2013;36(1):21-31. https://doi.org/10.1111/jfq.12009

54. Mariod AA. Effect of essential oils on organoleptic (smell, taste and texture) properties of food. In: Preedy VR, editor. Essential oils in food preservation, flavor and safety. Cambridge, MA, USA: Academic Press; 2016. pp. 131-7. https://doi.org/10.1016/b978-0-12-416641-7.00013-4 